\title{
The effect of red blood cell transfusion on tissue oxygenation and microcirculation in severe septic patients
}

\author{
Farid Sadaka*, Ravi Aggu-Sher, Katie Krause, Jacklyn O’Brien, Eric S Armbrecht and Robert W Taylor
}

\begin{abstract}
Background: Microcirculation plays a vital role in the development of multiple organ failure in severe sepsis. The effects of red blood cell (RBC) transfusions on these tissue oxygenation and microcirculation variables in early severe sepsis are not well defined.
\end{abstract}

Methods: This is a prospective, observational study of patients with severe sepsis requiring RBC transfusions of one to two units of non-leukoreduced RBCs for a hemoglobin < 7.0, or for a hemoglobin between 7.0 and 9.0 with lactic acidosis or central venous oxygen saturation $<70 \%$. This study took place in a 54-bed, medical-surgical intensive care unit of a university-affiliated hospital. Thenar tissue oxygen saturation was measured by using a tissue spectrometer on 21 patients, and a vaso-occlusive test was performed before and 1 hour after transfusion. The sublingual microcirculation was assessed with a Sidestream Dark Field device concomitantly on 11 of them.

Results: RBC transfusion resulted in increase in hemoglobin (7.23 $( \pm 0.87)$ to $8.75( \pm 1.06) \mathrm{g} / \mathrm{dl} ; p<0.001)$. RBC transfusion did not globally affect near-infrared spectrometry (NIRS)-derived variables. However, percent change in muscle oxygen consumption was negatively correlated with baseline $(r=-0.679, p=0.001)$. There was no statistically significant correlation between percent change in vascular reactivity and baseline $(p=0.275)$. There was a positive correlation between percent change in oxygen consumption and percent change in vascular reactivity $(r$ $=0.442, p=0.045$ ). In the 11 patients, RBC transfusion did not globally affect NIRS-derived variables or SDF-derived variables. There was no statistically significant correlation between percent change in small vessel perfusion and baseline perfusion $(r=-0.474, p=0.141)$, between percent change in small vessel flow and baseline flow $(r=$ $-0.418, p=0.201)$, or between percent change in small vessel perfusion and percent change in small vessel flow ( $r$ $=0.435, p=0.182$.

Conclusions: In a small sample population, muscle tissue oxygen consumption, microvascular reactivity and sublingual microcirculation were globally unaltered by RBC transfusion in severe septic patients. However, muscle oxygen consumption improved in patients with low baseline and deteriorated in patients with preserved baseline. Future research with larger samples is needed to further examine the association between RBC transfusion and outcomes of patients resuscitated early in severe sepsis, with an emphasis on elucidating the potential contribution of microvascular factors.

\section{Introduction}

In the United States, approximately 750,000 cases of sepsis occur each year, of which at least 225,000 are fatal. One study that evaluated the epidemiology of sepsis between 1979 and 2000 demonstrated an 8.7\% increase in the annual incidence of sepsis. The cost of

\footnotetext{
* Correspondence: Farid.Sadaka@Mercy.Net

St. John's Mercy Medical Center, St. Louis University, St. Louis, MO, USA
}

management of one septic patient has been estimated at $\$ 50,000$, amounting to annual costs of approximately $\$ 17$ billion. Sepsis is the second-leading cause of death in noncoronary intensive care units (ICUs) and the tenth leading cause of death overall. Organ failure occurs in approximately one third of patients with sepsis and severe sepsis is associated with an estimated mortality rate of $30-50 \%$. Seventy percent of patients with

\section{Springer}

() 2011 Sadaka et al; licensee Springer. This is an Open Access article distributed under the terms of the Creative Commons Attribution License (http://creativecommons.org/licenses/by/2.0), which permits unrestricted use, distribution, and reproduction in any medium, provided the original work is properly cited. 
three or more organ failures (classified as severe sepsis or septic shock) die [1-8].

Red blood cell transfusion is one of the most commonly used interventions in the ICU to treat severe anemia, which often occurs in sepsis. In the United States, more than 14 million units of packed red blood cells (RBCs) are administered annually, many of which are administered in the ICU [9]. Approximately 40-80\% of $\mathrm{RBC}$ transfusions in the ICU are not given for bleeding, but rather for low hemoglobin levels, for a decrease in physiological reserve, or for alterations in tissue perfusion $[10,11]$. In addition, $\mathrm{RBC}$ transfusion is recommended as part of early goal-directed therapy for patients with severe sepsis [12].

Patients with sepsis develop alterations in microvascular circulation, tissue oxygenation, and oxygen metabolism, all of which play a major role in the development of organ failure. Orthogonal polarization spectral (OPS) and sidestream dark field (SDF) imaging devices both provide high-contrast images of underlying microvasculature [13]. Using these devices, investigators have reported that the microcirculation is markedly altered in sepsis, alterations are more severe in nonsurvivors, and persistent microvascular alterations are associated with development of multiple organ failure and death [14-17]. The sublingual microcirculation has been the most extensively studied in patients with critical illness and sepsis.

Another noninvasive technique used is near-infrared spectrometry (NIRS) [18,19], which measures skeletal muscle tissue hemoglobin concentration and oxygen saturation before and after stagnant ischemia. Tissue ischemia is normally followed by arteriolar dilation and a temporary rise in local blood flow, a phenomenon termed reactive hyperemia $(\mathrm{RH})$. $\mathrm{RH}$ is impaired in patients with severe sepsis [20,21]. Using NIRS, investigators have shown that oxygen consumption (during stagnant ischemia) and microvascular reactivity $(\mathrm{RH})$ are altered in sepsis, are more severe in nonsurvivors, and persistence is associated with development of multiple organ failure and death [22-25].

The primary objective of this study was to evaluate the effect of RBC transfusion in severe septic patients on sublingual microvascular perfusion and flow using SDF and on muscle tissue oxygenation, oxygen consumption, and microvascular reactivity using NIRS. A secondary objective was to correlate the variables obtained from NIRS with those obtained from SDF.

\section{Methods}

\section{Subjects}

This prospective, observational study included 21 severe septic patients according to standard definition [26]. All patients received $\mathrm{RBC}$ transfusion for a hemoglobin <
7.0, or for a hemoglobin between 7.0 and 9.0 with lactic acidosis, or central venous oxygen saturation $<70 \%$. All patients were clinically euvolemic (by CVP and/or echocardiogram) and in the first 12 hours of sepsis. Exclusion criteria included $\mathrm{RBC}$ transfusion in the preceding 72 hours, peripheral vascular disease, liver cirrhosis, age $<18$ years, active bleeding, shock secondary to any other cause (cardiogenic, hemorrhagic, obstructive), and pregnancy. Hemodynamic, NIRS-derived, and SDFderived variables were obtained immediately before (baseline) and 1 hour after transfusion of 1 unit of packed RBCs. During the study period, no bedside procedures were performed, doses of vasopressor and sedative agents were kept constant, and the patient's position in bed (head of bed at 30 degrees elevation) was not changed. This study was approved by the Institutional Review Board at St. John's Mercy Medical Center with waiver of written informed consent (\# 09-953).

\section{Red blood cell transfusion characteristics}

Packed red blood cell units were obtained from the blood bank (St. John's Mercy Medical Center). None of the RBC units transfused in this study were leukoreduced. Storage solution (saline-adenine-glucose-mannitol) was added to RBCs before storage. The storage period of RBCs is allowed up to 42 days.

\section{Measurements}

The temperature, heart rate, arterial pressure, central venous pressure (when available), hemoglobin, central venous oxygen saturation, lactic acid, and arterial blood gases were recorded before and 1 hour after transfusion. The Acute Physiology and Chronic Health Evaluation II (APACHE II) score [27] was obtained at admission to the ICU, and the Sequential Organ Failure Assessment score [28] was obtained on the study day. The length of RBC storage before transfusion was noted in each case. NIRS measurements were obtained on all patients. SDF measurements were obtained for 11 patients. SDF measurements could not be obtained for all patients due to technical difficulties or safety concerns (i.e., some patients were not intubated, some were not sedated sufficiently).

\section{NIRS measurements and analysis}

The thenar tissue oxygen saturation $\left(\mathrm{StO}_{2}\right)$ and the tissue hemoglobin index (THI), an indicator of the blood volume in the region of the microvasculature sensed by the NIRS probe [29], were measured using a tissue spectrometer (InSpectra ${ }^{\mathrm{TM}}$ Model 650; Hutchinson Technology Inc., Hutchinson, MN, USA). This device uses reflectance mode probes to measure scattered light reflected at some distance from where the light is transmitted into the thenar muscle. Sample measurement signals were updated every 2 seconds. 
During a period of hemodynamic stability (mean arterial pressure $>65 \mathrm{mmHg}$ and no change in vasopressor doses for 2 hours), the NIRS probe was placed on the skin of the thenar eminence and a sphygmomanometer cuff was placed around the arm over the brachial artery. A large bore tube/cuff that inflates and deflates in less than one second was used to avoid cuff inflation and deflation from affecting the slope measurements. After a 3-minute period necessary to stabilize the $\mathrm{StO}_{2}$ signal, arterial inflow was stopped by inflation of the cuff to $50 \mathrm{mmHg}$ above the systolic arterial pressure. After 3 minutes of ischemia the cuff pressure was released, and $\mathrm{StO}_{2}$ was continuously recorded for another 3 minutes (reperfusion period). Continuous measurements of the $\mathrm{StO}_{2}$ and $\mathrm{THI}$ were obtained during the vaso-occlusive test. Baseline $\mathrm{StO}_{2}$ and THI were recorded before the ischemic period and THI was recorded after 1 minute of occlusion. During occlusion, we calculated the $\mathrm{StO}_{2}$ desaturation slope (\%/minute) obtained from the regression line of the first minute of $\mathrm{StO}_{2}$ decay after occlusion [29]. This is a representation of oxygen consumption. During the reperfusion phase, the $\mathrm{StO}_{2}$ upslope (\%/second) was obtained from the regression line of the first 14 seconds of increased $\mathrm{StO}_{2}$ (seven $\mathrm{StO}_{2}$ values) following the ischemic period. This $\mathrm{StO}_{2}$ upslope of the reperfusion phase was used to quantify the intensity of the reactive hyperemic response following release of the occluding cuff. The percent change in recovery (upslope) was calculated as the difference between the $\mathrm{StO}_{2}$ upslopes of the reperfusion phase after and before transfusion divided by the $\mathrm{StO}_{2}$ upslope before transfusion. Muscle oxygen consumption (NIRVO2) was calculated as the product of the inverse value of the $\mathrm{StO}_{2}$ desaturation slope and the mean THI over the first minute of arterial occlusion [29] and is expressed in arbitrary units:

NIRVO2 $=($ StO2 desaturation slope -1$) \times($ THIstart cuff + THI 1 min $)] / 2$

Percent change in NIRVO2 (downslope) was calculated as the difference between the NIRVO2 values after and before transfusion divided by NIRVO2 values before transfusion.

\section{SDF measurements and analysis}

Sidestream dark field imaging was performed by using a handheld device that illuminates an area of interest. Light is emitted by a circle of light-emitting diodes. The reflected light is returned through the inner image-conducting core, which is optically isolated from the light-emitting diodes and caught on camera. Although assessing the microcirculation is based on light absorption by the hemoglobin contained in RBCs, this technique remains valid in anemia, as well as during acute changes in hemoglobin concentration [30]. Sidestream dark field imaging and semiquantitative analysis were performed as described in detail elsewhere [31]. In short, video images (Microscan; Microvision Medical, Amsterdam, the Netherlands) were captured via connection to a laptop computer. After the removal of saliva and other secretions using gauze, the device was gently applied (without significant pressure) to the lateral side of the tongue, in an area approximately $1.5-4 \mathrm{~cm}$ from the tip of the tongue. Three video recordings of 20 seconds in duration each at two time points (i.e., baseline and 1 hour posttransfusion) were analyzed by dividing the image into four equal quadrants. Quantification of flow (microvascular flow index-MFI) was scored per quadrant, for each size group of microvessel diameter: small (10-25 microns), medium (25-50 microns), and large (50-100 microns). Quantification of flow $(0=$ no flow, $1=$ intermittent flow, 2 = sluggish flow, and $3=$ continuous flow) was recorded. Microvascular flow index was calculated as the sum of each quadrant score divided by the number of quadrants in which the vessel type was visible. The final MFI was averaged over a maximum of 12 quadrants (three regions, four quadrants per region) derived from the overall flow impressions of all vessels with a particular range of diameter in a given quadrant. The heterogeneity index was calculated, following the method of Trzeciak and colleagues [16], as the difference between the highest and lowest MFI, divided by the mean MFI of all sublingual sites at a single time point. Calculation of total (small) vessel density was performed with the AVA 3.0 software package (MicroVision Medical, Amsterdam, The Netherlands), as described and validated recently [32] using a cutoff diameter for small vessels $<20$ microns. After stabilization of the images using the AVA 3.0 software, we defined the perfused (small) vessel density (PVD) and the proportion of perfused (small) vessels (PPVs) in terms of the number and percentage of crossings with perfused (small) vessels per total length of three equidistant horizontal and three equidistant vertical lines (De Backer score), or as total length of perfused vessels divided by total surface of area $\left(\mathrm{mm} / \mathrm{mm}^{2}\right)$. To reduce observer measurement bias, sidestream darkfield images were analyzed off-line and in a blinded fashion by one of the investigators (FS), who was blinded to the patient's clinical course and the order of the sequences.

Percent change in PPV was calculated as the difference between the PPV values after and before transfusion divided by PPV values before transfusion. Percent change in MFI was calculated as the difference between the MFI values after and before transfusion divided by MFI values before transfusion. 


\section{Analysis}

Descriptive statistics were performed for the full and subgroup samples to assess similarities in patient characteristics, including age, gender, source of infection(s), age of blood, APACHE II score, and discharge status (i. e., mortality). Changes in hemodynamic and other observed measurements taken before (pre) and 1 hour after (post) the transfusion were assessed by a paired $t$ test. Mean, standard deviation and $p$ value were reported for each comparison. Analysis for the full sample and subgroup were conducted separately. A Pearson correlation coefficient (PCC) was calculated to describe the association between percent change in NIRVO2 (downslope), baseline NIRVO2 (downslope), percent change in recovery (upslope), and baseline upslope using subjects in the full sample. This method was repeated for the subgroup with additional comparisons, including percent change in PPV for small vessels vs. baseline PPV, percent change in MFI, percent change in NIRVO2 (downslope), and percent change in recovery (upslope). Percent change in MFI for small vessels was correlated with baseline MFI, percent change in NIRVO2 (downslope) and percent change in recovery (upslope). All analyses were conducted with SPSS/ PASW version 18 (Chicago, IL) by an investigator (EA) who was not involved with data collection or analysis of sidestream darkfield images.

\section{Results}

The study included 21 severe septic patients with NIRSderived data (full sample), 11 of whom also had SDFderived data (subgroup sample; Table 1). The median APACHE II scores were 24 and 25 for the full sample and the subgroup sample respectively, and in-hospital mortality was $47.6 \%$ and $45.6 \%$, respectively. No transfusion-related adverse reactions were observed during the study. The mean arterial pressure increased from 69.67 $\mathrm{mmHg}( \pm 8.76 \mathrm{mmHG})$ to $73.52 \mathrm{mmHg}( \pm 11.08$ $\mathrm{mmHg} ; p=0.08)$ in the full sample, and from 67.36 $\mathrm{mmHg}( \pm 7.97 \mathrm{mmHG})$ to $73.18 \mathrm{mmHg}( \pm 12.16$ mmHg; $p=0.02$ ) in the subgroup sample (Table 2). The median RBC storage time was 32 days (21-39) in the full sample and 32 days (22-39) in the subgroup sample.

\section{Full sample}

In the full sample, blood transfusion resulted in increase in hemoglobin $(7.23 \mathrm{~g} / \mathrm{dl}( \pm 0.87 \mathrm{~g} / \mathrm{dl})$ to $8.75 \mathrm{~g} / \mathrm{dl}( \pm$ $1.06 \mathrm{~g} / \mathrm{dl} ; p<0.001$; Table 2). Red blood cell transfusion did not globally affect NIRS-derived variables (Table 2; Figure 1A,B). However, percent change in NIRVO2 was negatively correlated with baseline NIRVO2 $(r=-0.679$, $p=0.001$; Figure 2A). There was no statistically significant correlation between percent change in recovery (upslope) and baseline recovery upslope ( $p=0.275$;
Table 1 Characteristics of the study groups

\begin{tabular}{|c|c|c|}
\hline & $\begin{array}{l}\text { Full sample } \\
(n=21)\end{array}$ & $\begin{array}{l}\text { Subgroup }^{b} \\
(n=11)\end{array}$ \\
\hline Age $(y r)$ & $71(41-87)$ & $73(55-83)$ \\
\hline Male gender, \% & $11(52.4)$ & $5(45.5)$ \\
\hline APACHE II score & $24(17-39)$ & 25 (20-39) \\
\hline SOFA score & $8(3-17)$ & $9(3-16)$ \\
\hline \multicolumn{3}{|l|}{ Source of infection, \% } \\
\hline Lung & $11(52.4)$ & $3(27.3)$ \\
\hline Abdomen & $6(28.6)$ & $4(36.4)$ \\
\hline Urinary tract & $3(14.3)$ & $3(27.3)$ \\
\hline Line & $1(4.7)$ & $1(9.0)$ \\
\hline \multicolumn{3}{|l|}{ Vasopressors/inotropes dose ${ }^{c}$} \\
\hline Norepinephrine, mcg/min & $10 ; 10(2-40)$ & $6 ; 10(2-25)$ \\
\hline Dobutamine, $\mathrm{mcg} / \mathrm{kg} / \mathrm{min}$ & $4 ; 5(2.5-10)$ & $2 ; 3.7(2.5-5)$ \\
\hline \multicolumn{3}{|l|}{ Sedation/analgesic dose $e^{c}$} \\
\hline Midazolam, mg/hr & $7 ; 2(2-4)$ & $4 ; 2(2-4)$ \\
\hline Fentanyl, mcg/hr & $8 ; 100(50-400)$ & $4 ; 100(50-400)$ \\
\hline $\begin{array}{l}\text { Human recombinant activated protein } \\
\text { C, } \%\end{array}$ & 14.3 & 27.3 \\
\hline Renal replacement therapy, \% & 33.3 & 27.3 \\
\hline Red blood cell storage time (days) & $32(21-39)$ & $32(22-39)$ \\
\hline In-hospital mortality, \% & 47.6 & 45.6 \\
\hline
\end{tabular}

Data are presented as median (25th to 75th percentiles) or $n$ (\%).

APACHE, Acute Physiology and Chronic Health Evaluation; SOFA, Sequential Organ Failure Assessment.

${ }^{\mathrm{a}}$ Full sample, all with NIRS data.

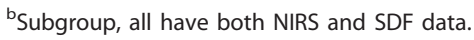

cn; dose.

Figure 2B). There was a positive correlation between percent change in NIRVO2 and percent change in the recovery upslope $(r=0.442, p=0.045$; Figure $3 \mathrm{~A})$.

\section{Subgroup sample}

In the subgroup sample, blood transfusion resulted in increase in hemoglobin $(7.48 \mathrm{~g} / \mathrm{dl}( \pm 0.83 \mathrm{~g} / \mathrm{dl})$ to $8.95 \mathrm{~g} /$ $\mathrm{dl}( \pm 1.12 \mathrm{~g} / \mathrm{dl}) ; p<0.001$; Table 2$)$. Red blood cell transfusion did not globally affect NIRS-derived variables or SDF-derived variables (Tables 2 and 3; Figure 1C,D). Similar to the full sample, percent change in NIRVO2 was negatively correlated with baseline NIRVO2 ( $\mathrm{r}=$ $-0.689, p=0.019$; Figure $2 \mathrm{~A}$ ). There was no statistically significant correlation between percent change in the recovery upslope and baseline recovery upslope ( $p=$ 0.407 ; Figure 2B). There was a positive correlation between percent change in NIRVO2 and percent change in the recovery upslope $(r=0.775, p=0.005$; Figure $3 \mathrm{~A})$. These findings suggest that the subgroup sample is similar in most observable regards to the full sample.

\section{THI results}

THI variables behaved exactly similar to $\mathrm{StO} 2$ variables (data not shown). THI correlated with $\mathrm{StO}_{2}$. For example, in the full sample before transfusion, THI positively 
Table 2 Physiologic and near-infrared spectroscopy-derived variables before and 1 hour after red blood cell transfusion

\begin{tabular}{|c|c|c|c|c|c|c|c|c|}
\hline & \multicolumn{4}{|c|}{ Full Sample } & \multicolumn{4}{|c|}{ Subgroup } \\
\hline & \multirow[b]{2}{*}{$\mathrm{n}$} & \multirow{2}{*}{$\begin{array}{l}\text { Baseline } \\
\text { Mean (SD) }\end{array}$} & \multicolumn{2}{|c|}{$\begin{array}{l}\text { After } \\
\text { Transfusion }\end{array}$} & \multirow[b]{2}{*}{$\mathrm{n}$} & \multirow{2}{*}{$\begin{array}{l}\text { Baseline } \\
\text { Mean (SD) }\end{array}$} & \multicolumn{2}{|c|}{$\begin{array}{l}\text { After } \\
\text { Transfusion }\end{array}$} \\
\hline & & & $\begin{array}{l}\text { Mean } \\
\text { (SD) }\end{array}$ & $p$ & & & $\begin{array}{l}\text { Mean } \\
\text { (SD) }\end{array}$ & $p$ \\
\hline Hemoglobin (g/dl) & 21 & $7.2(0.8)$ & $8.7(1.1)$ & 0.00 & 11 & $7.5(0.8)$ & $8.9(1.1)$ & 0.00 \\
\hline Heart Rate (beats/min) & 21 & $\begin{array}{l}91 \\
(15)\end{array}$ & $91(15)$ & 0.34 & 11 & $91(18)$ & $89(18)$ & 0.14 \\
\hline Temperature $\left({ }^{\circ} \mathrm{F}\right)$ & 21 & $97.8(1.2)$ & $97.7(1.2)$ & 0.65 & 11 & $98.1(1.2)$ & $98.1(1.2)$ & 0.96 \\
\hline Mean arterial pressure $(\mathrm{mmHg})$ & 21 & $69.6(8.7)$ & $73.5(11.1)$ & 0.08 & 11 & $67.3(7.9)$ & $73.2(12.1)$ & 0.02 \\
\hline Central venous pressure $(\mathrm{mmHg})$ & 12 & $16(5.7)$ & $16.2(4.3)$ & 0.79 & 7 & $15.2(4.3)$ & $16.1(5)$ & 0.34 \\
\hline Lactate $(\mathrm{mmol} / \mathrm{l})$ & 12 & $4.1(3.5)$ & $3.9(3.4)$ & 0.47 & 6 & $3.7(2.1)$ & $3.8(2.4)$ & 0.73 \\
\hline Arterial partial pressure of oxygen $(\mathrm{mmHg})$ & 6 & $124.6(97.6)$ & $95.2(29.2)$ & 0.49 & 3 & $164(137.1)$ & $101(38)$ & 0.5 \\
\hline $\mathrm{pH}$ & 6 & $7.3(0.1)$ & $7.3(0.1)$ & 0.62 & 3 & $7.3(0.1)$ & $7.3(0.1)$ & 0.24 \\
\hline Central venous oxygen saturation (\%) & 10 & $59.1(9.2)$ & $63.8(8.8)$ & 0.11 & 6 & $62.3(9.2)$ & $64.6(8.9)$ & 0.48 \\
\hline $\mathrm{SaO}_{2} / \mathrm{FiO}_{2}$ & 21 & $\begin{array}{l}264.1 \\
(114.8)\end{array}$ & $\begin{array}{l}270.9 \\
(97.2)\end{array}$ & 0.46 & 11 & $\begin{array}{l}249.5 \\
(105.9)\end{array}$ & $\begin{array}{l}259.1 \\
(91.5)\end{array}$ & 0.19 \\
\hline Thenar tissue oxygen saturation (\%) & 21 & $76.2(9.3)$ & $75.8(8.1)$ & 0.80 & 11 & $76.8(8.4)$ & $75.8(8.8)$ & 0.69 \\
\hline Tissue hemoglobin index (arbitrary units) & 21 & $10.7(3.4)$ & $12.2(3.5)$ & 0.01 & 11 & $10.9(3.1)$ & $12.2(4.1)$ & 0.07 \\
\hline $\begin{array}{l}\text { Thenar tissue oxygen saturation upslope of the reperfusion phase } \\
\text { (\%/second) }\end{array}$ & 21 & $2.5(1.3)$ & $2.6(1.5)$ & 0.39 & 11 & $2.2(1)$ & $2.1(1.1)$ & 0.78 \\
\hline Muscle oxygen consumption (arbitrary units) & 21 & $\begin{array}{l}113.6 \\
(56.43)\end{array}$ & $\begin{array}{l}124.1 \\
(43.6)\end{array}$ & 0.26 & 11 & $104.4(41.1)$ & $\begin{array}{l}112.5 \\
(40.3)\end{array}$ & 0.5 \\
\hline
\end{tabular}

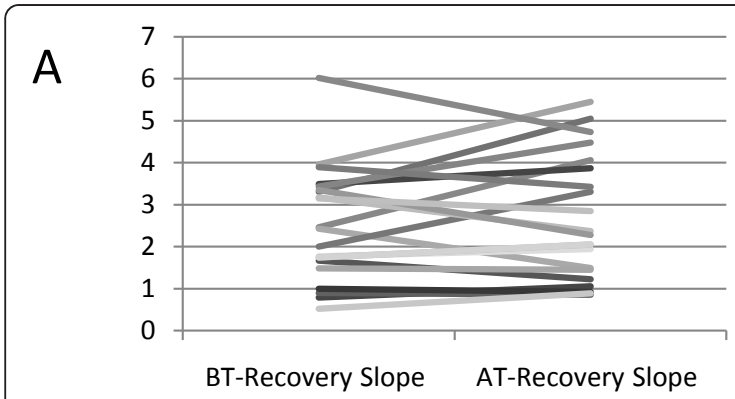

C

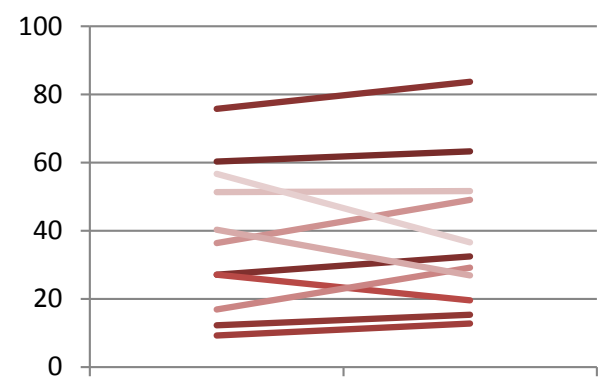

BT- PPV Sm vessels AT- PPV Sm vessels
B
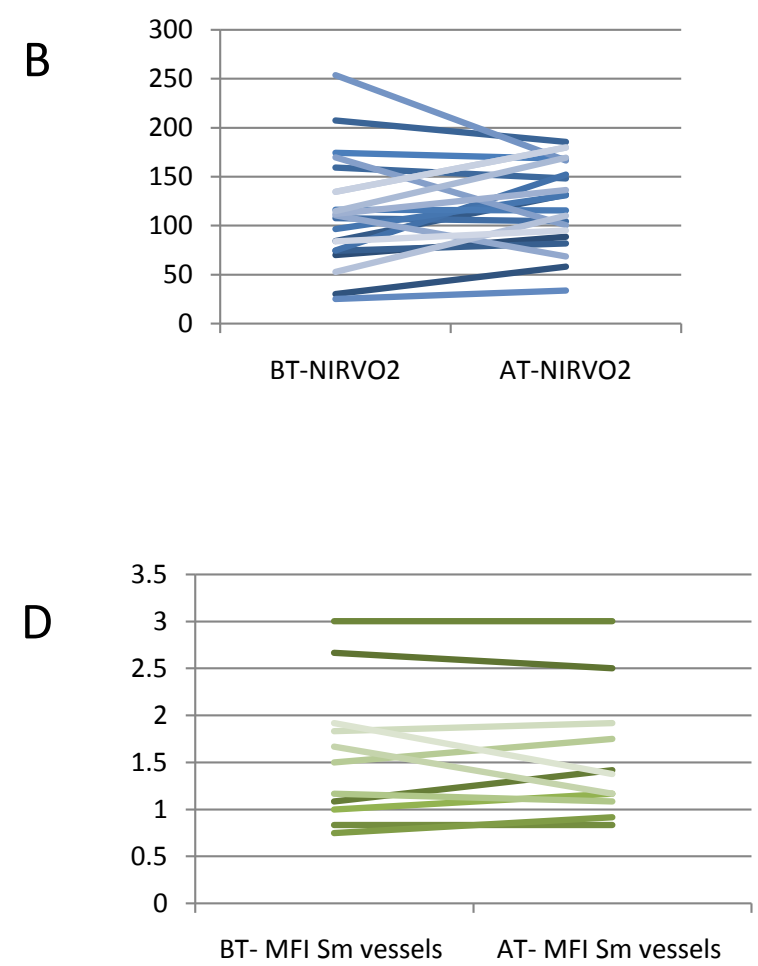

Figure 1 Tissue oxygenation and microcirculation variables for individual patients from before and after transfusion. A Recovery slopes for individual patients from before and after transfusion for full sample. B NIRVO2 for individual patients from before and after transfusion for full sample. C PPV small vessels for individual patients from before and after transfusion for subgroup sample. D MFI small vessels for individual patients from before and after transfusion for subgroup sample. 


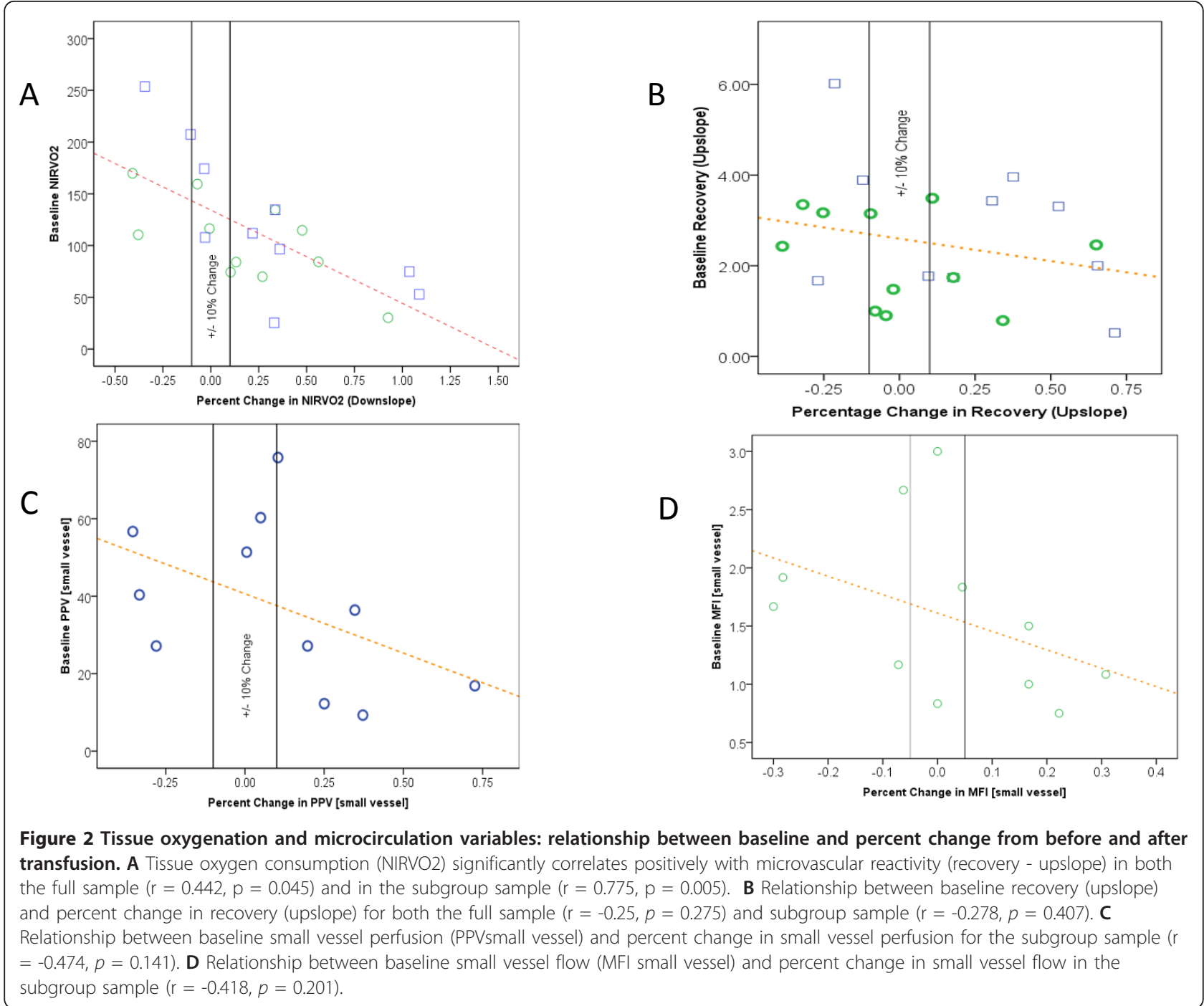

correlated with $\mathrm{StO}_{2}(\mathrm{r}=0.47, p=0.03)$. THI increased after transfusion in the full sample (Table 2), but not in the subgroup sample. There was no correlation between THI and hemoglobin levels before transfusion $(\mathrm{r}=0.11$, $p=0.64)$ or after transfusion $(\mathrm{r}=0.16, p=0.49)$.

\section{Correlations between variables from NIRS and SDF}

There was no statistically significant correlation between percent change in small vessel PPV and baseline small vessel PPV ( $\mathrm{r}=-0.474, p=0.141$; Figure $2 \mathrm{C}$ ). There was no statistically significant correlation between percent change in small vessel MFI and baseline small vessel MFI $(r=-0.418, p=0.201$; Figure $2 \mathrm{D})$. There was no statistically significant correlation between percent change in small vessel PPV and percent change in small vessel MFI ( $\mathrm{r}=0.435, p=0.182$; Figure 3B). Although there was no significant correlation between NIRSderived variables (NIRVO2, recovery upslope) and SDF- derived variables (PPV, MFI), all changes in NIRSderived variables occurred in the same direction as SDFderived variables (Figures 2 and 3).

\section{Discussion}

The main finding of our study was that RBC transfusion had no global effect on muscle oxygen saturation, oxygen consumption, microvascular reactivity, vessel perfusion, or microvascular flow in severe septic patients. However, there was considerable variance between subjects. There was an improvement in oxygen consumption in patients with altered oxygen consumption at baseline and deterioration in oxygen consumption in patients with preserved baseline oxygen consumption.

Prospective studies in ICU patients showed a higher mortality rate in patients receiving $\mathrm{RBCs}$ than in those not receiving RBCs. These results suggest that a more restrictive transfusion strategy was safe in the ICU 
A

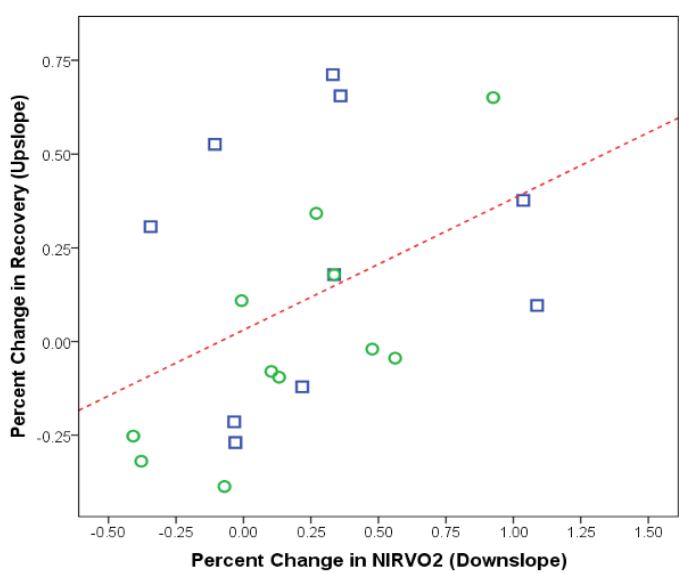

B

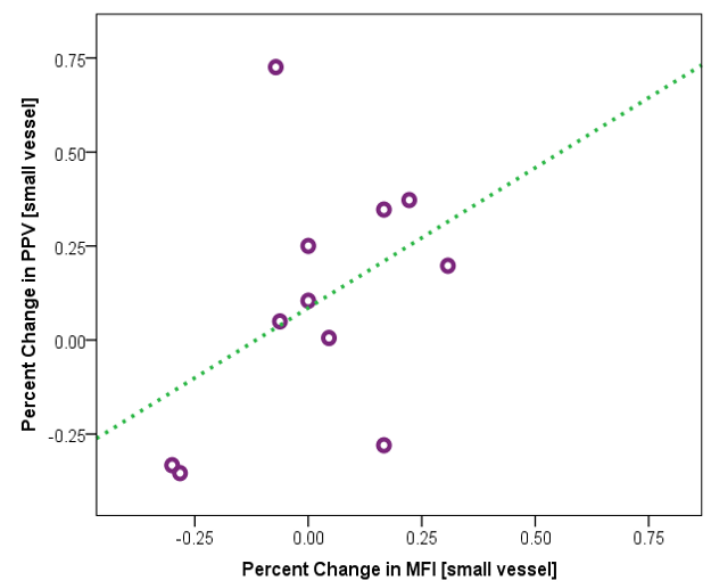

Figure 3 Correlations among Tissue oxygenation variables and Microcirculation variables. A Tissue oxygen consumption (NIRVO2) significantly correlates positively with microvascular reactivity (recovery - upslope) in both the full sample $(r=0.442, p=0.045)$ and in the subgroup sample $(r=0.775, p=0.005)$. B Small vessel Microvascular Flow Index (MFIsmall-marker of flow) correlates positively with proportion of perfused small vessels (PPVsmall-marker of perfusion) in the subgroup sample (not statistically significant; $r=0.435, p=0.182$ ).

population and might be beneficial for some patients $[33,34]$. Guidelines published as part of the Surviving Sepsis Campaign [12] have endorsed use of RBCs in the treatment of patients with severe sepsis who show evidence of hypoperfusion. This recommendation is primarily based on data published by Rivers et al. [35] who evaluated a bundle approach to patients in severe sepsis. Red blood cell transfusion to obtain a hematocrit of $30 \%$ is included in this bundle for patients with a central venous oxygen saturation $<70 \%$. Patients achieving this goal had better outcomes than patients who did not reach the goal. The specific effect of transfusion was not evaluated in this study; however, because the investigation was designed to assess the overall bundle rather than its component parts. Using NIRS or SDF, several investigators have reported that microcirculation is markedly altered in sepsis, that these alterations are more severe in nonsurvivors than in survivors, that persistent microvascular alterations are associated with development of multiple organ failure and death, and that microvascular alterations are the most sensitive and specific predictor of outcome in septic patients [14-17,22-25]. Our goal was to study the effect of RBC transfusion on microvascular variables in severe septic patients using both NIRS and SDF.

The effects of RBC transfusion on the microcirculation in sepsis could be numerous. Several studies have demonstrated that RBC rheology is impaired (increased

Table 3 Sidestream Dark Field-derived microcirculatory variables before and $1 \mathrm{hr}$ after red blood cell transfusion

\begin{tabular}{|c|c|c|c|c|c|}
\hline \multirow{2}{*}{$\begin{array}{c}\text { Subgroup } \\
\text { Measurement }\end{array}$} & \multicolumn{2}{|l|}{ Baseline } & \multicolumn{3}{|c|}{ After transfusion } \\
\hline & Vessel size & $\mathrm{n}$ & Mean (SD) & Mean (SD) & $p$ \\
\hline Total vessel density $\left(\mathrm{mm} / \mathrm{mm}^{2}\right)$ & Small & 11 & $22.4(5.9)$ & $21.5(5.5)$ & 0.36 \\
\hline Total vessel density $\left(\mathrm{mm} / \mathrm{mm}^{2}\right)$ & Large & 11 & $3.4(1.3)$ & $3.9(1)$ & 0.2 \\
\hline Total vessel density $\left(\mathrm{mm} / \mathrm{mm}^{2}\right)$ & All & 11 & $25.7(6.4)$ & $25.4(6)$ & 0.73 \\
\hline Perfused vessel density $\left(\mathrm{mm} / \mathrm{mm}^{2}\right)$ & Small & 11 & $9.5(4.8)$ & $9.4(4.8)$ & 0.91 \\
\hline Perfused vessel density $\left(\mathrm{mm} / \mathrm{mm}^{2}\right)$ & Large & 11 & $3(1.5)$ & $3.7(1.2)$ & 0.09 \\
\hline Perfused vessel density $\left(\mathrm{mm} / \mathrm{mm}^{2}\right)$ & All & 11 & $12.5(5.4)$ & $13.3(4.7)$ & 0.53 \\
\hline Proportion of perfused vessels (\%) & Small & 11 & $37.6(21.5)$ & $38.2(21.8)$ & 0.85 \\
\hline Proportion of perfused vessels (\%) & Large & 11 & 100 & 100 & 1 \\
\hline Proportion of perfused vessels (\%) & All & 11 & $51.6(23.8)$ & $53.9(20.9)$ & 0.45 \\
\hline De Backer score $(\mathrm{n} / \mathrm{mm})$ & & 11 & $14.7(3.8)$ & $14.8(3.5)$ & 0.91 \\
\hline Microvascular Flow Index & Small & 11 & $1.6(0.7)$ & $1.6(0.7)$ & 0.76 \\
\hline Microvascular flow index & All & 11 & $2.3(0.4)$ & $2.4(0.3)$ & 0.3 \\
\hline Heterogeneity index (\%) & & 11 & $0.3(0.2)$ & $0.4(0.3)$ & 0.19 \\
\hline
\end{tabular}


aggregation, decreased deformability, alterations of RBC shape) in sepsis [36-39]. These alterations could contribute to the microcirculatory alterations observed in critically ill patients [39]. RBC also can act as oxygen sensor, which can modulate tissue oxygen flow variables - by the release of the vasodilators, nitric oxide [40,41], or ATP [42]. This release of vasodilators from RBCs during hypoxia could be impaired during storage and/or sepsis. Storage of RBCs decreases levels of 2,3-diphosphoglycerate and adenosine triphosphate (ATP) levels with a resultant increase in oxygen affinity and a decrease in the ability of hemoglobin to offload oxygen. Morphological changes in erythrocytes occur during storage which may result in increased fragility, decreased viability, and decreased deformability of red blood cells. A release of a number of substances occurs during storage resulting in such adverse systemic responses as fever, cellular injury, alterations in regional and global blood flow, and organ dysfunction. Several studies have demonstrated that transfusion with RBCs that have been stored for long time periods is associated with poorer oxygen delivery than is transfusion with fresher cells [43-49]. The median RBC storage time in our study was 32 days, which is similar to other studies. A recent literature review reported no strong association between duration of storage and complications [50]. In addition, Creteur et al. [51] using NIRS and Sakr et al. [52] using OPS showed that RBC storage time had no influence on the microvascular response to red blood cell transfusion.

Our study differs from Creteur et al. in several points. We studied severe septic patients, whereas Creteur et al. studied hemodynamically stable patients, $41 \%$ of whom had sepsis. We transfused older (median RBC storage time $=32$ vs. 18 days) RBCs; ours were all nonleukoreduced, whereas theirs were all leukoreduced. We used both NIRS and SDF in our study, whereas they only used NIRS. Our study also differed from Sakr et al. We transfused older blood (median RBC storage time $=32$ vs. 24 days); ours were all nonleukoreduced, whereas theirs were all leukoreduced. We used both NIRS and SDF in our study, whereas they only used OPS (older version of SDF). In a very recent review on monitoring the microcirculation in critically ill patients, De Backer et al. concluded that a monitoring device should be able to detect capillary perfusion, flow, and heterogeneity of perfusion. This is best achieved with handheld microvideoscopic techniques, such as OPS and SDF. They also concluded that the use of vascular occlusion tests with laser Doppler or NIRS investigates microvascular reactivity, another important, but different, aspect of microvascular function. De Backer suggested that "Combining techniques may be of interest in the future" [53]. To our knowledge, our study is the only human study that employed both techniques in monitoring the impact of an intervention on the microcirculation. Each of these three studies showed similar findings. Creteur et al. demonstrated an improvement in microvascular reactivity and tissue oxygen consumption in patients with altered microvascular reactivity and tissue oxygen consumption at baseline and deterioration in microvascular reactivity and tissue oxygen consumption in patients with preserved baselines [51]. Sakr et al. showed an improvement in sublingual microvascular perfusion in patients with altered perfusion at baseline and deterioration in sublingual microvascular perfusion in patients with preserved baseline perfusion [52]. All showed no global effect of RBC transfusion on the microvascular variables.

In a recent study that evaluated perioperative $R B C$ transfusions in patients who underwent cardiac surgery using SDF and sublingual reflectance spectrophotometry, Yuruk et al. showed that RBC transfusion improved sublingual microcirculatory density, but not perfusion velocity, and improved microcirculatory oxygen saturation [54]. Their study included a totally different patient population, patients with (relatively) healthy microcirculation.

Why do some patients show beneficial effects of RBC transfusions while others do not? Friedlander et al. observed that RBC transfusions improved RBC deformability in patients with sepsis, probably by replacing rigid, endogenous RBCs by less dysfunctional, exogenous RBCs [55]. Transfusions may therefore be deleterious when performed in patients with preserved deformability, vasoreactivity, perfusion, and/or flow but may be favorable when performed in patients in whom these variables are markedly altered.

Interestingly, RBC transfusion-induced changes in NIRVO2, in the recovery upslope of the reperfusion phase, in PPV, and in MFI were all in the same direction, suggesting that an improvement or worsening in microvascular reactivity, microvascular perfusion, and microvascular blood flow may be associated with an increase or decrease in local muscle oxygen consumption, respectively.

NIRS-derived variables showed changes in the same direction compared with SDF-derived variables (Figures 2 and 3). These changes were not, however, statistically significant. This is likely secondary to a small sample size. In fact that these two devices monitor different aspects of the microvasculature, as well as different organs also may have contributed. Hence, using both devices may be complimentary and a point of strength for this study.

Our study has its limitations. Our small sample size and the fact that some variables could not be obtained in some patients is an obvious limitation. The limited number of patients does not make it possible to 
determine whether initial deranged microcirculatory parameters could really influence the final response to RBC transfusion. NIRS monitors hemoglobin oxygen saturation in arterioles, venules, and capillaries in the measured volume of tissue, and the relative contributions of arterial, venous, and capillary blood within the measured volume of tissue cannot be determined. NIRS does not measure microcirculatory blood flow or perfusion. It also targets muscle tissue, specifically the thenar muscle. SDF monitors the capillaries and venules (not arterioles), but this device monitors the actual flow and perfusion and their heterogeneity in the microvessels. SDF data could be analyzed only semiquantitatively. SDF targets the sublingual mucosa, which shares a similar embryonic origin with the digestive mucosa (always involved pathologically in sepsis) but may not reflect other microcirculatory beds. Our measurements were restricted to $1 \mathrm{hr}$ after RBC transfusion, therefore, later alterations due to transfusion may have been missed. However, longer follow-up periods are practically difficult because of inevitable changes in therapy and procedures in these critically ill patients that could themselves affect the microcirculation and other outcomes. THI increased after transfusion in the full sample (Table 2), which could alter the NIRVO2 measurements (refer to NIRS measurements and analysis above). THI does not reflect systemic hemoglobin levels as a result of Fahraeus effect, heterogeneous flow distributions, and local conditions (such as vasoconstriction and edema) [56,57]. In addition, Doerschug et al. showed that the THI was not related to blood hemoglobin concentration in patients with severe sepsis [22]. Similarly, in our study, there was no correlation between THI and hemoglobin levels before transfusion $(\mathrm{r}=0.11$, $p=0.64)$ or after transfusion $(\mathrm{r}=0.16, p=0.49)$. Moreover, despite the increase in THI in the full sample, there was an improvement in NIRVO2 in patients with altered baseline and deterioration in NIRVO2 in patients with preserved baseline in both the full sample and the subgroup sample, suggesting that this relationship is real. Because $\mathrm{StO}_{2}$ represents the average of the hemoglobin oxygen saturation in arterioles, venules and capillaries in the whole tissue sample, NIRS is not able to demonstrate changes on microvascular density or heterogeneity. As a result, we must continue to explore the meaning of reactive hyperemia as a surrogate of microvascular functionality.

\section{Conclusions}

The effects of RBC transfusions on microvascular oxygenation, consumption, reactivity, perfusion, and flow are quite variable and may be dependent on baseline values. In this observational study of limited size, no effect of $\mathrm{RBC}$ transfusion on any measured microcirculation variables in severe septic patients was observed. This study does suggest that better means of identifying the need for transfusion are needed and that blindly transfusing to an arbitrarily set (and high) $\mathrm{Hb}$ may be detrimental. This study involves a small sample of patients, based on which strong recommendations cannot be made. Future research with larger samples is needed to further examine the association between RBC transfusion and outcomes of patients resuscitated early in severe sepsis, with an emphasis on elucidating the potential contribution of microvascular factors.

\section{Financial/nonfinancial disclosures}

All authors report that no potential conflicts of interest exist with any companies/organizations whose products or services may be discussed in this article.

\section{Acknowledgements}

The authors acknowledge Margaret Cytron, R.N., for helping with data collection for this study and Eric S. Armbrecht, PhD, for statistical support.

\section{Authors' contributions}

FS contributed to conceiving the study, acquiring and managing the data, analyzing the data and interpreting the results, drafting and revising the manuscript, and approving the manuscript in its final form. RA, KK, and JO contributed to acquiring and managing the data, revising the manuscript, and approving the manuscript in its final form. EA contributed to performing statistical analysis, acquiring and managing the data, revising the manuscript, and approving the manuscript in its final form. RT contributed to analyzing the data and interpreting the results, revising the manuscript, and approving the manuscript in its final form.

\section{Competing interests}

The authors declare that they have no competing interests.

Received: 21 August 2011 Accepted: 8 November 2011

Published: 8 November 2011

\section{References}

1. Martin GS, Mannino DM, Eaton S, Moss M: The epidemiology of sepsis in the United States from 1979 through 2000. N Engl J Med 2003, 348:1546-1554.

2. Brun-Buisson C, Doyon F, Carlet J: Incidence, risk factors, and outcome of severe sepsis and septic shock in adults: a multicenter prospective study in intensive care units. JAMA 1995, 274:968-974.

3. Karlsson S, Ruokonen E, Varpula T, Ala-Kokko TI, Pettilä V, Finnsepsis Study Group: Long-term outcome and quality-adjusted life years after severe sepsis. Crit Care Med 2009, 37:1268-1274.

4. Angus DC, Linde-Zwirble WT, Lidicker J, Clermont G, Carcillo J, Pinsky MR: Epidemiology of severe sepsis in the United States: analysis of incidence, outcome, and associated costs of care. Crit Care Med 2001, 29:1303-1310.

5. Chalfin DB, Holbein ME, Fein AM, Carlon GC: Cost-effectiveness of monoclonal antibodies to gram-negative endotoxin in the treatment of gram-negative sepsis in ICU patients. JAMA 1993, 269:249-254.

6. Wheeler AP, Bernard GR: Treating patients with severe sepsis. N Engl J Med 1999, 340:207-214.

7. Parrillo JE, Parker MM, Natanson C, Suffredini AF, Danner RL, Cunnion RE, Ognibene FP: Septic shock in humans: advances in the understanding of pathogenesis, cardiovascular dysfunction, and therapy. Ann Intern Med 1990, 113:227-242

8. Angus DC, Wax RS: Epidemiology of sepsis: an update. Crit Care Med 2001, 29(Suppl 7):S109-116.

9. Comprehensive report on blood collection and transfusion in the US in 2001. [http://www.nbdrc.org] 
10. Vincent JL, Baron JF, Reinhart K, Gattinoni L, Thijs L, Webb A, MeierHellmann A, Nollet G, Peres-Bota D: Anemia and blood transfusion in critically ill patients. JAMA 2002, 288:1499-1507.

11. Corwin HL, Gettinger A, Pearl RG, Fink MP, Levy MM, Abraham E, Maclntyre NR, Shabot MM, Duh MS, Shapiro MJ: The CRIT Study: anemia and blood transfusion in the critically ill - current clinical practice in the United States. Crit Care Med 2004, 32:39-52.

12. Dellinger RP, Levy MM, Carlet JM, Bion J, Parker MM, Jaeschke R, Reinhart K, Angus DC, Brun-Buisson C, Beale R, Calandra T, Dhainaut JF, Gerlach H, Harvey M, Marini JJ, Marshall J, Ranieri M, Ramsay G, Sevransky J, Thompson BT, Townsend S, Vender JS, Zimmerman JL, Vincent JL: Surviving Sepsis Campaign: International guidelines for management of severe sepsis and septic shock: 2008 [published correction appears in Crit Care Med 2008; 36:1394-1396]. Crit Care Med 2008, 36:296-327.

13. Goedhart PT, Khalilzada M, Bezemer R, Merza J, Ince C: Sidestream Dark Field (SDF) imaging: a novel stroboscopic LED ring-based imaging modality for clinical assessment of the microcirculation. Optics Express 2007, 15:15101-15114.

14. De Backer D, Creteur J, Preiser JC, Dubois MJ, Vincent JL: Microvascular blood flow is altered in patients with sepsis. Am J Respir Crit Care Med 2002, 166:98-104.

15. Spronk PE, Ince C, Gardien MJ, Mathura KR, Oudemans-van Straaten HM, Zandstra DF: Nitroglycerin in septic shock after intravascular volume resuscitation. Lancet 2002, 360:1395-1396.

16. Trzeciak S, Dellinger RP, Parrillo JE, Bajaj J, Abate NL, Arnold RC, Colilla S, Zanotti S, Hollenberg SM: Early microcirculatory perfusion derangements in patients with severe sepsis and septic shock: relationship to hemodynamics, oxygen transport, and survival. Ann Emerg Med 2007, 49:88-98.

17. Sakr Y, Dubois MJ, De Backer D, Creteur J, Vincent JL: Persistant microvasculatory alterations are associated with organ failure and death in patients with septic shock. Crit Care Med 2004, 32:1825-1831.

18. De Blasi RA, Ferrari M, Natali A, Conti G, Mega A, Gasparetto A: Noninvasive measurement of forearm blood flow and oxygen consumption by nearinfrared spectroscopy. J App/ Physiol 1994, 76:1388-1393.

19. De Blasi RA, Quaglia E, Ferrari M: Skeletal muscle oxygenation monitoring by near infrared spectroscopy. Biochem Int 1991, 25:241-245.

20. Astiz ME, DeGent GE, Lin RY, Rackow EC: Microvascular function and rheologic changes in hyperdynamic sepsis. Crit Care Med 1995, 23:265-271.

21. Neviere R, Mathieu D, Chagnon JL, Lebleu N, Millien JP, Wattel F: Skeletal muscle microvascular blood flow and oxygen transport in patients with severe sepsis. Am J Respir Crit Care Med 1996, 153:191-195.

22. Doerschug K, Delsing A, Schmidt G, Haynes WG: Impairments in microvascular reactivity are related to organ failure in human sepsis. Am J Physiol Heart Circ Physiol 2007, 293:H1065-H1071.

23. Pareznik R, Knezevic R, Voga G, Podbregar M: Changes in muscle tissue oxygenation during stagnant ischemia in septic patients. Intensive Care Med 2006, 32:87-92.

24. Creteur J, Carollo T, Soldati G, Buchele G, De Backer D, Vincent JL: The prognostic value of muscle StO2 in septic patients. Intensive Care Med 2007, 33:1549-1556.

25. Skarda D, Mulier K, Myers D, Taylor JH, Beilman GJ: Dynamic Near-Infrared Spectroscopy Measurements in Patients with Severe Sepsis. Shock 2007, 27:348-353.

26. Levy MM, Fink MP, Marshall JC, Abraham E, Angus D, Cook D, Cohen J, Opal SM, Vincent JL, Ramsay G: 2001 SCCM/ESICM/ACCP/ATS/SIS International Sepsis Definitions Conference. Crit Care Med 2003, 31:1250-1256

27. Knaus WA, Draper EA, Wagner DP, Zimmerman JE: APACHE II: A severity of disease classification system. Crit Care Med 1985, 13:818-829.

28. Vincent JL, Moreno J, Takala J, Willatts S, De Mendonça A, Bruining H, Reinhart CK, Suter PM, Thijs LG: The SOFA (Sepsis-related Organ Failure Assessment) score to describe organ dysfunction/failure. Intensive Care Med 2000, 22:707-710.

29. Mulier KE, Skarda DE, Taylor JH, McGraw MK, Gallea BL, Beilman GJ: Nearinfrared spectroscopy in patients with severe sepsis: correlation with invasive hemodynamic measurements. Surg Infect (Larchmt) 2008, 9:515-519.

30. Wang $P$, Hauptman JG, Chaudry $\mathrm{IH}$ : Hemorrhage produces depression in microvascular blood flow which persists despite fluid resuscitation. Circ Shock 1990, 32:307-318.
31. De Backer D, Hollenberg S, Boerma C, Goedhart P, Büchele G, OspinaTascon G, Dobbe I, Ince C: How to evaluate the microcirculation: report of a round table conference. Crit Care 2007, 11:R101.

32. Dobbe JGG, Streekstra GJ, Atasever B, van Zijderveld R, Ince C: Measurement of functional microcirculatory geometry and velocity distributions using automated image analysis. Med Biol Eng Comput 2008, 46:659-670.

33. Hebert PC, Wells G, Blajchman MA, Marshall J, Martin C, Pagliarello G, Tweeddale M, Schweitzer I, Yetisir E: A multicenter, randomized, controlled clinical trial of transfusion requirements in critical care. $N$ Engl J Med 1999, 340:409-417.

34. Vincent JL, Baron JF, Reinhart K, Gattinoni L, Thijs L, Webb A, MeierHellmann A, Nollet G, Peres-Bota D, ABC(Anemia and Blood Transfusion in Critical (are) Investigators: Anemia and blood transfusion in critically ill patients. JAMA 2002, 288:1499-1507.

35. Rivers E, Nguyen B, Havstad S, Ressler J, Muzzin A, Knoblich B, Peterson E, Tomlanovich M, for the Early Goal-Directed Therapy Collaborative Group: Early goal-directed therapy in the treatment of severe sepsis and septic shock. N Engl J Med 2001, 345:1368-1377.

36. Powell RJ, Machiedo GW, Rush BFJ: Decreased red blood cell deformability and impaired oxygen utilization during human sepsis. Am Surg 1993, 59:65-68.

37. Baskurt OK, Gelmont D, Meiselman HJ: Red blood cell deformability in sepsis. Am J Respir Crit Care Med 1998, 157:421-427.

38. Hurd TC, Dasmahapatra KS, Rush BFJ, Machiedo GW: Red blood cell deformability in human and experimental sepsis. Arch Surg 1988, 123:217-220.

39. Reggiori G, Occhipinti G, De Gasperi A, Vincent $J$, Piagnerelli M: Early alterations of red blood cell rheology in critically ill patients. Crit Care Med 2009, 37:3041-3046.

40. Cosby K, Partovi KS, Crawford JH, Patel RP, Reiter CD, Martyr S, Yang BK, Waclawiw MA, Zalos G, Xu X, Huang KT, Shields H, Kim-Shapiro DB, Schechter AN, Cannon RO, Gladwin MT: Nitrite reduction to nitric oxide by deoxyhemoglobin vasodilates the human circulation. Nat Med 2003, 9:1498-1505

41. Jia L, Bonaventura C, Bonaventura J, Stamler JS: S-nitrosohaemoglobin: a dynamic activity of blood involved in vascular control. Nature 1996, 380:221-226.

42. Ellsworth ML: The red blood cell as an oxygen sensor: what is the evidence? Acta Physiol Scand 2000, 168:551-559.

43. Fitzgerald RD, Martin CM, Dietz GE, Doig GS, Potter RF, Sibbald WJ: Transfusing red blood cells stored in citrate phosphate dextrose adenine- 1 for 28 days fails to improve tissue oxygenation in rats. Crit Care Med 1997, 25:726-732.

44. Marik PE, Sibbald WJ: Effect of stored-blood transfusion on oxygen delivery in patients with sepsis. JAMA 1993, 269:3024-3030.

45. Raat NJ, Verhoeven AJ, Mik EG, Gouwerok CW, Verhaar R, Goedhart PT, de Korte $D$, Ince $C$ : The effect of storage time of human red cells on intestinal microcirculatory oxygenation in a rat isovolemic exchange model. Crit Care Med 2005, 33:39-45.

46. Zallen G, Offner PJ, Moore EE, Blackwell J, Ciesla DJ, Gabriel J, Denny C, Silliman CC: Age of transfused blood is an independent risk factor for post injury multiple organ failure. Am J Surg 1999, 178:570-572.

47. Ho J, Sibbald WJ, Chin-Yee IH: Effects of storage on efficacy of red cell transfusion: When is it not safe? Crit Care Med 2003, 31:S687-S697.

48. Peek CC, Moore GL, Bolin RB: Adenine in blood preservation. Crit Rev Clin Lab Sci 2006, 18:173-212.

49. Tinmouth A, Fergusson D, Yee IC, ABLE Investigators, Canadian Critical Care Trials Group: Clinical consequences of red cell storage in the critically ill. Transfusion 2006, 46:2014-2027.

50. Lelubre C, Piagnerelli M, Vincent JL: Association between duration of storage of red blood cells and morbidity and mortality in adult patients: myth or reality? Transfusion 2009, 49:1384-1394.

51. Creteur J, Neves AP, Vincent JL: Near-infrared spectroscopy technique to evaluate the effects of red blood cell transfusion on tissue oxygenation. Critical Care 2009, 13(Suppl 5):S11.

52. Sakr Y, Chierego M, Piagnerelli M, Verdant C, Dubois MJ, Koch M, Creteur J, Gullo A, Vincent JL, De Backer D: Microvascular response to red blood cell transfusion in patients with severe sepsis. Crit Care Med 2007, 35:1639-1644. 
53. De Backer D, Ospina-Tascon G, Salgado D, Favory R, Creteur J, Vincent JL: Monitoring the microcirculation in the critically ill patient: current methods and future approaches. Intensive Care Med 2010, 36:1813-1825.

54. Yuruk K, Almac E, Bezemer R, Goedhart P, de Mol B, Ince C: Blood Transfusions recruit the microcirculation during cardiac surgery. Transfusion 2011, 51:961-967.

55. Friedlander $\mathrm{MH}$, Simon R, Machiedo GW: The relationship of packed cell transfusion to red blood cell deformability in systemic inflammatory response syndrome patients. Shock 1998, 9:84-88.

56. Klitzman B, Duling BR: Microvascular hematocrit and red cell flow in resting and contracting striated muscle. Am J Physiol 1979, 237: $\mathrm{H} 481-\mathrm{H} 490$.

57. Sarelius $\mathrm{H}$, Duling BR: Direct measurement of microvessel hematocrit, red cell flux, velocity, and transit time. Am J Physiol 1982, 243:H1018-H1026.

doi:10.1186/2110-5820-1-46

Cite this article as: Sadaka et al.: The effect of red blood cell transfusion on tissue oxygenation and microcirculation in severe septic patients. Annals of Intensive Care 2011 1:46.

\section{Submit your manuscript to a SpringerOpen ${ }^{\odot}$ journal and benefit from:}

- Convenient online submission

- Rigorous peer review

- Immediate publication on acceptance

- Open access: articles freely available online

- High visibility within the field

- Retaining the copyright to your article

Submit your next manuscript at $\gg$ springeropen.com 